\title{
Lost in Translation: Culture-bound Lexical Items in English Subtitles of the Rap Songs by Indian Rapper 'Badshah' in Bollywood Movies from 2016-2021
}

\author{
Ritika Sinha \\ Assistant Professor of English, Goswami Ganesh Dutta Sanatan Dharma College, Sector 32, \\ Chandigarh. E-mail: ritika.sinha@ggdsd.ac.in, ORCID: 0000-0003-1746-316X
}

\begin{abstract}
Subtitling, a subfield of translation studies has witnessed a recent upsurge in India. The rise of subtitling services can be attributed to the fact that the number of viewers from outside the country is increasing phenomenally, thanks to the global streaming platforms. Subtitling is an art; it involves translation of the language of the video to another language with an objective to retain the temper of the original message for the target audience. The subtitler is faced with the daunting task of preserving the idiom of the source text (ST) and the target text (TT). Since, the meaning in both source and target language is profoundly affected by the cultural context, it is important to undertake the practice of translation while respecting and reflecting cultural ethos of each language. This research aims to investigate the English subtitles of selected famous rap sequences by Indian rapper 'Badshah' in Bollywood songs released from 2016 to 2021. With an aim to assess the quality of translation of the selected song sequences, an analysis is made of the sematic peculiarities that are lost in translation from Hindi/Punjabi to English. The loss can be mainly attributed to Hindi and Punjabi cultural references or culture-bound terms which do not have a suitable equivalent lexical item in English language.
\end{abstract}

Keywords: Translation, Subtitles, Translation studies, Bollywood subtitling, rap songs, English Subtitles

\section{Introduction}

Language is the bedrock of interaction between individuals, society and culture. Language and literature has been the object of considerable interdisciplinary research and continue to be so. The recent booming of the global streaming services have revolutionised the field of audio-visual media and necessitated the need to transcend linguistic borders and cultures by incorporating new technologies, one of them being advanced visualization along with the process of translation.

Back in the first decade of 2000, India was essentially a dubbing market. Subtitling was in its infancy, a last-minute job which was entrusted with novice writers who attempted literal translations. The resultant subtitles were most of the times incomprehensible, and even laughable. Around 2017, the growing popularity of the global streaming platforms such as Netflix and Amazon Prime revolutionized the field of subtitling in India. With an aim to expand the audience

This Open Access article is published under a Creative Commons Attribution Non-Commercial 4.0 International License (http://creativecommons.org/licenses/by-nc/4.0/), which permits non-commercial re-use, distribution, and reproduction in any medium, provided the original work is properly cited. For citation use the DOI. For commercial re-use, please contact editor@rupkatha.com. 
base for their existing content library, they sought content localisation. The easiest cost-effective solution was subtitling, compared to dubbing which would be time consuming and cost much more. Resultantly, there has been a phenomenal growth of companies called Language Service Providers or LSPs which are presently translating content mainly from seven major regional languages into English.

This has instigated research in translation studies in the Indian context. The subtitler is confronted with the variance in the cultural context of both the source and the target language; it is he who often struggles to replace the Indian cultural bound terms and references with an apt word in English language when subtitling a regional language media. Thus, maintaining the quality of subtitles is critical for successfully projecting our films as world cinema and to make viewers better understand foreign content in a familiar language.

The Present research primarily focuses on selected rap song sequences by Indian rapper 'Badshah' in Bollywood Movies from 2016-2021. For anyone who has ever gone to an Indian function with music or dancing, might have surely tapped on a Bollywood rap song by Bohemia, Honey Singh or Badshah, famous for extravagant beats originating from Bhangra. Badshah is an Indian rapper, singer, film producer and businessman known for his Hindi, Haryanvi, and Punjabi songs. He has appeared in Forbes India's Celebrity 100 in 2017, 2018 and 2019 as one of the highest-paid celebrities in India and as the only rapper in the list. The 2020 survey by Music business worldwide has ranked him as world's No.1 songwriter on YouTube, whose channel on YouTube has over 2 million subscribers and has attracted over 261 million views.

\section{Review of Literature}

In 1990, Bassnet \& Lefevere co-published "Translation, History and Culture", formally putting forward the idea of cultural turn in translation. The cultural approach of Translation Studies is a theoretical and methodological shift in Translation Studies. It gained recognition in the early nineties and is primarily associated with the work of Susan Bassnett, André Lefevere and, later, Lawrence Venuti. For Bassnett \& Lefevere (1990) translation is primarily contextual. It is a fact of history and a product of the target culture, and as such it cannot be explained through the mapping of linguistic correspondence between languages, or judged with respect to universal standards of quality and accuracy.

Audio-visual translation studies (AVT) is concerned with translation that takes place in audio and/or visual settings, such as the cinema, television, video games and also some live events such as opera performances (Pedersen, 2010). The main translation modes are subtitling, film dubbing and voice-over, but also subtitling for the opera and theatre (Vervecken, 2012).

Subtitle is text written on the screen of the audio-visual work. Subtitles can be either in the same language as the audio, called intra-lingual subtitling or in another target language called interlingual subtitling. The task of the subtitler is demanding, requiring the use of specific strategies to retain the essence of language and to enhance the quality of the subtitles.

Subtitling, a distinct field of audio-visual translation, is different from dubbing. Dubbing, a form of screen translation, is an oral translation activity which utilises acoustic channel. Subtitling is a visual translation activity that involves superimposition of a written text onto the screen (Baker \& 
Hochel, 1998). According to O'Connell (2007), subtitling is "supplementing the original voice soundtrack by adding written text on screen".

However, subtitling is a demanding cognitive process that poses several difficulties and formal quantitative and textual qualitative challenges for the translator (Gottlieb, 1998). The formal constraints to subtitling are space limits, which is generally a maximum of 2 lines and 35 characters, and another issue is the average reading speed of the viewers. Therefore, the adherence to the process of synchronization is necessary to keep a uniform minimum interval between subtitles to facilitate reading. Another challenge is the visual cuts, one that a subtitle should not be retained on a screen during a shot change and, a clear margin should be left on either side of the visual cuts (Zojer, 2011).

Malenova (2015) classifies four restrictions in the process of subtitling; normative restrictions, social restrictions, personal restrictions, and physiological restrictions.

- Normative restriction is the problem of finding appropriate equivalents of the Source language word in the Target language.

- Social restrictions encompass the cultural dimension, and include lexical items and expressions like religious and ethical terms.

- Personal restrictions require the subtitler to translate in a detached manner. A biased translation, might affect "some unique variants of translation, and to making crucial mistakes" (Malenova, 2015).

- Physiological restriction is the varied ability of each translator in terms of perception and comprehension.

The daunting task for a subtitler is translating cultural references. Cultural references are related to culture-specific contexts such as geography, sociolinguistic aspects, history, and textual constraints and also include signs, gestures and symbols peculiar to language and culture. Ramière (2004) stated three types of cultural references; sociocultural, historical and extra linguistic references. Díaz-Cintas \& Remael (2007) use the expression 'culture-bound terms' to refer to cultural references. The translation of these culture-bound terms is particularly challenging when it comes to subtitling. In other forms of written translation, footnotes, glosses, and many other translation strategies can be applied to explicate some culture-bound terms. However, these methods are not available in subtitling. The emotive words pose another challenge while translating cultural references (Zojer, 2011).

Díaz-Cintas \& Remael (2007) propose six strategies for translating cultural references or cultural bound terms

1. Transposition: Source language cultural items are subtitled into equivalent target language (TL) cultural concepts. The translated item may not be equivalent to the idiom of the source language but it sounds culturally acceptable in the target language.

2. Calque or literal translation: this is a literal translation accompanied with little changes.

3. Explication: The Subtitler attempts to explain the source language cultural item in a way that makes it comprehensible and accessible to the target audience. 
4. Cultural adaptation: The subtitler replaces the source language culture-bound item with another term in the source language itself because this replaced term has a target language cultural item that conveys a similar meaning

5. Generalizations: in this case, a subtitler decides to use a hypernym for a ST word in the target language.

6. Loan: this can happen with names that are transferred to the TL.

The study also aims to assess the quality of the subtitles. Bittner (2011) lay that it is difficult to assess the quality of translation, particularly that of subtitles. He lists six factors that affect the quality of subtitles; text form, culture, translator, source text (ST), politics and client. He defines the good quality in translation as "the perception of a translation as most appropriate within the context in which it functions".

The assessment models proposed by Reiss (1971/2000) and House $(1981,1997,2015)$ have been most extensively deployed to assess translated text. Reiss (1971/2000) viewed a text as operating at the level of communication. Translation is considered as a process of producing a text in the Target language which is functionally equivalent to the Source language text (Reiss, 1971/2000). House (2015) also proposed a quality assessment model in 1981, revised recently in 2015. Drawing on the Halliday's Systemic Functional Theory, this model advocates analysing parts of the ST and parts of the target text (TT) in terms of register and genre.

Gottlieb (2001) proposes that the quality of a subtitle can be assessed by analysing the translation of each verbal segment in terms of its stylistic and semantic values.

Pedersen (2017) proposes a quality assessment model named FAR, an acronym which stands for:

- Functional equivalence (do the subtitles convey speaker meaning?)

- Acceptability (do the subtitles sound correct and natural in the target language?)

- Readability (can the subtitles be read in a fluent and non-intrusive way?).

These three parameters are used to test the quality of translation and are based on an error analysis typology. Errors are classified into 'minor, 'standard' or 'serious' errors. Pedersen believes that stylistic errors are less serious than semantic errors which hamper the understanding of source text.

\section{Research Method}

This research is qualitative in nature, the audio-visual content of selected rap sequences by 'Badshah' in Bollywood movies from 2016 to 2021 and their English subtitles were examined to identify the translation strategies used and to assess the quality of the translation of cultural references. This study fits in the interpretive paradigm of a qualitative research, which is pertinent with the descriptive translation studies.

This study aims to identify the divergence in lexical items in subtitling the culture-bound terms in the selected Bollywood Punjabi rap song sequences. For this purpose, the data was collected from 5 Bollywood songs containing rap sequences by the famous Indian Rapper, 'Badshah', released between 2016-2021. The data of the study was selected in particular because these songs enjoy 
widespread audience in and across India and several videos of 'Badshah' have set records of most viewed videos online.

The rap snippets were qualitatively analysed to unearth the subtitling strategies employed in translation from Punjabi/Hindi to English. The main focus is on the Punjabi/ Hindi lexical items in the song under study and how these culturally bound textual items signal divergence and loss of meaning when translated into English. The study explores the issue of Translation divergence, a problem which occurs during translation between two languages of different origin. It mainly occurs when the output translation of one language into another language results in loss of linguistic temper.

The selected songs sequences have been numbered, and the title of the Bollywood movie they are a part of, have also been listed. For the convenience of presentation, both the lyrics of Punjabi/Hindi rap and English subtitles are given. (as they appear in the video). An assessment of the translated content is provided at the end of each subtitling category. The Punjabi/Hindi ST is presented in the first line (s) and the English TT in the second line (s).

\section{Discussion}

Today, filmmakers and producers see subtitles as a bridge to a wider audience. In India, bad subtitles have been ridiculed and have inspired memes and parodies. But in the last few years, there has been a remarkable change in how subtitles are written, because of streaming platforms and new markets. Subtitling for Indian Cinema is an art, particularly subtitling songs are a challenge for the subtitler can't mess with the rhyme, has to translate and be poetic at the same time! Also, importantly the subtitles should mirror cultural references.

1. Name of the Song Track: Garmi

Movie: Street Dancer 3D

Artists: Badshah, Neha kakkar

Released: 2020

\section{Streaming Platform: Amazon Prime}

Three couplets from the Song Track 'Garmi' have been analysed to ascertain the variance in the original rap sequence and the subsequent subtitles.

\begin{tabular}{|c|c|}
\hline $\begin{array}{c}\text { Rap sequence } \\
\text { (Hindi) }\end{array}$ & $\begin{array}{c}\text { Hilti Kamar Jaise Snake, } \\
\text { Teri Sundarta Pe Likh Doon Baby, } \\
\text { Do Phut Lamba Lekh. }\end{array}$ \\
\hline $\begin{array}{c}\text { English } \\
\text { Subtitle }\end{array}$ & I can write an essay on your beauty without taking a break. \\
\hline
\end{tabular}

The Subtitler takes liberty here by introducing the word 'break', for it rhymes with 'snake'. The Rap however, states the intent of the speaker to write a '2 feet long essay' rather than writing one 
without break! The minor alteration seems to be intentional; for the English subtitle here imparts a poetic character to the translation.

\begin{tabular}{|c|c|}
\hline $\begin{array}{c}\text { Rap } \\
\text { Sequence } \\
\text { (Hindi) }\end{array}$ & Mere Piche Marke Ashiq, Kitne Hi Mashoor Huwe. \\
\hline $\begin{array}{c}\text { English } \\
\text { Subtitle }\end{array}$ & Romeos have put their life for me at stake. \\
\hline
\end{tabular}

The data above signals a sematic error of omission, commonly committed in subtitles as the translator tries to stick to word limit and screen space. Omission occurs when the ST term is omitted and not rendered to the TT. The rap sequence in hindi, additionally states 'Kitne $H i$ Mashoor Huwe', which has not been subtitled in English in the song track. It means not only have 'Romeos put their life for me at stake' but they have also become famous for this act. (How heavenly charismatic the lady is!)

\begin{tabular}{|c|c|}
\hline $\begin{array}{c}\text { Rap Sequence } \\
\text { (Hindi) }\end{array}$ & Kar Doon Sau Bat Ki Ek, Legi Mujko Tu Matha Tek. \\
\hline English Subtitle & Getting to the point, you're going to make me wait. \\
\hline
\end{tabular}

A divergence is observed in the English Translation, 'you're going to make me wait' of Hindi phrase, 'Legi Mujko Tu Matha Tek. The dissonance arises as the subtitler uses generalisation while translating and overlooks the idiomatic expression, 'Matha Tek' which means the act of bowing down and touching the floor with one's forehead in reverence or submission. The Translation fails to deliver this impact by simply putting 'you're going to make me wait'. Generalisation implies that the culture-bound term is rendered less specifically in the TT than it is in the ST.

\section{Name of the Song Track: Koka}

Movie: Khandaani Shafakhana

Artists: Badshah, Jasbir Jassi, \& Dhvani Bhanushali

\section{Released: 2019}

Streaming Platform: Amazon Prime

This latest remix track is a famous Punjabi dance number. The name of the track itself 'Koka' has cultural connotations and is a beautiful rendition of Punjabi culture. Koka means, "nose pin" in English, it is an ornament or jewellery worn by most of the Indian girls. The popular movie songs in various other Indian languages have made the nose pin, the most happening fashion accessory, often associated with grace and beauty. 
7 Lost in Translation: Culture-bound Lexical Items in English Subtitles of the Rap Songs by Indian Rapper 'Badshah' in Bollywood Movies from 2016-2021

\begin{tabular}{|c|c|}
\hline $\begin{array}{c}\text { Rap Sequence } \\
\text { (Punjabi) }\end{array}$ & $\begin{array}{c}\text { Koka, Tera kujh-kujh kehnda Ni } \\
\text { Lehanga Tera lutt-putt lehnga Ni koka. }\end{array}$ \\
\hline English Subtitle & $\begin{array}{c}\text { Nose Pin says something } \\
\text { As your veil flutters in the wind. }\end{array}$ \\
\hline
\end{tabular}

Punjabi language has the characteristic feature of replicative words for which no corresponding translations exist in English language. Thus, the translation gap results in variation in the syntactic part of a sentence, though the meaning is generally preserved. The Punjabi repetitive words, 'kujhkujh'are translated into English as 'something'.

However, the second line of the English subtitle signals a lexical error that can shroud understanding of the TT and create misinterpretation. The Punjabi phrase uses the lexical item 'lehanga' which is an elaborately embroidered long flowing skirt worn with a top, usually on ceremonial occasions. The Punjabi lyrics use rhyming reduplication '/utt-putt' to convey the aesthetics of this costume which sways and robs the onlookers, again something that is lost in translation. The English Subtitle uses the word 'veil', which is a piece of cloth, worn usually by women over the head and shoulders and sometimes over the face; it is something that covers or hides something else. Therefore, the use of formal language to render informal information in the ST creates a translation lapse. Lexical divergence occurs due to unavailability of corresponding mapping for a word in source language to the target language.

\begin{tabular}{|c|c|}
\hline Rap Sequence (Punjabi) & Nau-lakha tere utte haar vaar doon. \\
\hline English Subtitle & Bring all the riches in the world for you. \\
\hline
\end{tabular}

Every country had its special culture which is rarely translated into other countries' culture. This has a direct repercussion on translation, often resulting in certain semantic elements in the ST which do not have an equivalent in the TT. The Punjabi lyrics stated above carry an important lexical item, 'vaar' which is an integral part of Punjabi traditions and ceremonies. 'Vaarna', or the blessing of money, is a practice wherein individuals, generally elders will wave money clockwise over the heads of the couple and then donate it to charity. This is done with the purpose of cleansing any negative energy that may be surrounding the bride and groom. The rap line 'Naulakha tere utte haar vaar doon' emotes exuberance and extravagance as the suitor will perform the custom of 'vaarna' on his lady love with a necklace worth nine lakhs. Quite an amount to ward evil and donate to charity! What is bothersome here is the unavailability of a cultural concept in English to emphatically describe the meaning of these lines. Linguistic research and translation studies claim that untranslatability occurs not only due to linguistic limits but also from cultural barriers within translation. Catford (1965) rationalised this theory in his book "Linguistic Theory of Translation":

"Cultural untranslatability arises when a situational feature, functionally relevant for the source language text, is completely absent from the culture of which the TL is a part." 
Popovic (1975) also assumes that there is a difference between linguistic and cultural untranslatability, an idea that he defends in "A Dictionary for the Analysis of Literary Translation":

"A situation in which the linguistic elements of the original cannot be replaced adequately in structural, linear, functional or semantic terms in consequence of a lack of denotation or connotation."

3. Name of the Song Track: Tere Naal Nachna

Movie: Nawabzaade

Artists: Badshah, Sunanda Sharma

Released: 2018

Streaming Platform: Amazon Prime

\begin{tabular}{|c|c|}
\hline Rap Sequence (Punjabi) & Hirni si aakhein baby sawla rang. \\
\hline English Subtitle & Eyes intoxicating, and body that mesmerises. \\
\hline
\end{tabular}

Yet again, the data shows lexical divergence. The word 'sawla' in the rap sequence means 'dark', 'dusky' which is translated into English subtitle; 'body that mesmerizes'. Although the ST too ascribes positive connotations while describing the skin tone of the lady as dusky, the English translation add more to what is given in the ST. Here, the subtitler uses 'explication' and 'addition' for the purpose of rendering some implicit meaning explicit. Addition happens when the translator adds some information that is latent to the ST for clarification purpose (Pedersen, 2005).

\begin{tabular}{|c|c|}
\hline Rap Sequence (Punjabi) & Addi maar ke vehda pattna. \\
\hline English Subtitle & Set the dance floor on Fire. \\
\hline
\end{tabular}

Punjabis are fun-loving people who believe in expressing their emotion with gusto. The carefree, unapologetic and larger-than-life language that Punjabi is, compliments its people perfectly. The language is spot-on and leaves no scope for mincing words; hyperbole is somewhat synonymous with Punjabi speakers and finds lucid expression particularly in their music.

After harvesting their wheat crops during the Vaisakhiseason, farmers perform Bhangra to showcase a sense of accomplishment and to welcome the new harvesting season, the vigour and vitality is unmatchable. The Punjabi line (addi maar ke vehda patna) carries the comparatively simmered English subtitle 'Set the dance floor on Fire', while the line actually means 'to dance with such vigour and power that even the touch of the heel would break the veranda floor. Surely, she seems to be a power-packed Punjabi damsel dancing!

\section{Name of the Song Track: Chull}

Movie: Kapoor \& Sons 
9 Lost in Translation: Culture-bound Lexical Items in English Subtitles of the Rap Songs by Indian Rapper 'Badshah' in Bollywood Movies from 2016-2021

Artists: Badshah, Fazilpuria, Sukriti Kakar, Neha Kakkar, Amaal Mallik

\section{Released: 2016}

\section{Streaming Platform: Netflix}

\begin{tabular}{|c|c|}
\hline $\begin{array}{c}\text { Rap Sequence } \\
\text { (Hindi) }\end{array}$ & $\begin{array}{c}\text { Bolti bandh meri, kahoon kya bhala } \\
\text { Kuchh bhi kahaa nahi jaaye. }\end{array}$ \\
\hline English Subtitle & I can't take it. \\
\hline
\end{tabular}

The English subtitle clearly reflects major omission which hinders the correction understanding of the ST. The rap sequence in question means 'I am speechless because I am indecisive about what to speak'. The translation 'I can't take it' is a weak attempt to represent the ST.

\begin{tabular}{|c|c|}
\hline $\begin{array}{c}\text { Rap Sequence } \\
\text { (Hindi) }\end{array}$ & $\begin{array}{c}\text { Kya naache tu dilli, hile hai London, } \\
\text { Matak matak jaise raveena tendon. }\end{array}$ \\
\hline English Subtitle & Your move it like a sexy star, \\
& Your moves are your swag, \\
& You move it like a sexy star. \\
\hline
\end{tabular}

Songs, which involve wordplay and local nuances, pose a major challenge to translation. The rap sequence and the corresponding English Subtitle exhibit a lot of variance which can be attributed to geographical allusions and reference to a Bollywood film star 'Raveena Tandon' in the ST lyrics. Hyperbole is evident as the literal translation states 'that when you dance in Delhi, the after-effects are felt by people in London. Righty so, music transcends geographical boundaries!

The subtitler can take liberties due to cultural differences and line length but the challenge is to play with language in a way that even if there is a deviation from ST, the emotion is retained.

5. Name of the Song Track: Baby ko Bass pasand hai

Movie: Sultan

Artists: Badshah, Shalmali Kholgade, Vishal Dadlani

Released: 2016

Streaming Platform: Netflix 


\begin{tabular}{|c|c|}
\hline Rap Sequence (Hindi) & Haaye re mere bhole panchi. \\
\hline English Subtitle & Oh my poor little poodle. \\
\hline
\end{tabular}

Why a 'panchi', meaning 'bird' in the rap lyric is translated to 'poodle', a dog breed in the English translation? There is categorical divergence; 'poor little puppy' in the TT was an 'innocent bird' in the ST.

\begin{tabular}{|c|c|}
\hline Rap Sequence (Hindi) & Song suna ke English ke. \\
\hline English Subtitle & Luring me with love songs. \\
\hline
\end{tabular}

It is noteworthy as the subtitle writer chooses to use the term 'love songs', replacing 'English songs' as mentioned in the rap sequence. In India, English language is placed on a pedestal and defines the class status in our society. People who can communicate properly in English feel they are a notch higher than others. The attitude explains why the Hindi lyricist talks about 'luring with English songs' which is substituted by love songs to fit the understanding of global audiences.

\section{Conclusion}

As the OTT revolution has picked up in India, this business has grown exponentially. Since the initial translation was word-to-word or literal translation, ignoring the cultural background, the translated texts were obscure and disordered. Even until now, many translators are just at war between literal translation and free translation, irrespective of the essential element-'culture'.

Divergence issues mainly arise due to the incongruity of source and target language. This paper focuses on the discrepancies that we observe while translating our input text in Hindi and Punjabi to English language. The quality assessment reflects divergence in most subtitles, particularly dissonance in lexical items. Often the culture- specific vocabulary results in untranslatable term. Also, it seems that the subtitlers employed simplification of syntax to save space on the screen. Though the subtitler has the freedom to take a few liberties with the original, but here it can be clearly observed that omission, generalisation and culturally neutral explication has resulted in loss of meaning and effect. The foremost reason for lapses in translation of culture-specific lexical items occurs because these languages under study belong to the different language families. While, English is one of the West Germanic languages; Hindi and Punjabi are part of the IndoAryan family. The loss can also be attributed to insufficient knowledge of the target language or the source language, with all its linguistic peculiarities and turns of expression.

There is another challenge in translating audio-visual media; when a spoken text is changed to a written text, it stipulates different stylistic and structural features. Written texts also show higher lexical density in comparison to spoken texts (Zojer, 2011). Further, those written texts should have the flavour of a spoken language, which undoubtedly is stumbled upon in the English subtitling of the Punjabi rap sequences analysed in this study. 
Translation is a creative and intelligent task, and not as simple as it might appear to an unacquainted person. It's far more complicated than just finding an equivalent word in another language. Cultural translation must reflect cultural differences and respect the source culture. The subtitlers must have impeccable writing skills in the target language and an excellent knowledge of the source language and culture to make sure that no nuance is missed. A good subtitler will act as a guide to a culture and the most delicate aspect of their job is certainly the translation of songs. A dialogue may only convey part of what is happening on screen; the subtitler must additionally figure out whether any unstated information needs to be supplied and pick on nonverbal clue to facilitate representative subtitles which would not confuse a viewer who is not Indian. No part of the dialogue, however small, should be lost in translation.

\section{Referencing}

Baker, M., \& Hochel, B. (1998). Dubbing. In M. Baker (Ed.), Routledge Encyclopedia of Translation Studies (pp. 74-77). Routledge.

Bassnett, S., \& Lefevere, A. (Eds.). (1990). Translation, history and culture. Pinter Publishers.

Bassnett, S., \& Lefevere, A. (1998). Constructing cultures essays on literary translation. Multilingual Matters. Bittner, H. (2011). The Quality of Translation in Subtitling. Trans-Kom, 4(1), 76-87.

Catford, J. C. (1965). A Linguistic Theory of Translation. In Oxford University Press. Oxford University Press.

Díaz-Cintas, J., \& Remael, A. (2007). Audiovisual translation: subtitling. In Target (Issue 2). St. Jerome Pub.

Gottlieb, H. (1998). Subtitling. In M. Baker (Ed.), Routledge Encyclopedia of Translation Studies (pp. 244247). Routledge.

House, J. (2015). Translation Quality Assessment: Past and Present. Routledge.

House, J. (2001). Quality of translation. In M. Baker (Ed.), Routledge Encyclopedia of Translation Studies (pp. 399-404). Routledge.

House, J. (1997). A model for translation quality assessment: A model revisited. Gunten Narr.

House, J. (1981). A model for translation quality assessment (2nd ed.). Narr.

Italiano, F., \& Rössner, M. (2012). Translation: Narration, Media and the Staging of Differences. In Translatio/n. Narration, Media and the Staging of Differences. Transcript Verlag.

Malenova, E. D. (2015). Translating Subtitles-Translating Cultures. Journal of Siberian Federal University. Humanities \& Social Sciences, 12(8), 2891-2900. https://doi.org/10.17516/1997-1370-2015-8-122891-2900

O'Connell, E. (2007). Screen Translation. In P. Kuhiwczak \& K. Littau (Eds.), A Companion to Translation Studies (Issue C, pp. 123-133). Multilingual Matters Ltd.

http://www.freewebs.com/dennis_rusu/a_companion_to_translation_studies.pdf

Pedersen, J. (2010). Audiovisual translation - in general and in Scandinavia. Perspectives: Studies in Translation Theory and Practice, 18(1), 1-22. https://doi.org/10.1080/09076760903442423

Pedersen, J. (2005). How is Culture Rendered in Subtitles? In H. Gerzymisch-Arbogast \& S. Nauert (Eds.), MuTra 2005 - Challenges of Multidimensional Translation: Conference Proceedings (pp. 1-18). 
Pedersen, J. (2017). The FAR model: assessing quality in interlingual subtitling. The Journal of Specialised Translation, 28, 210-229.

Popovic, A. (1975). Dictionary for the analysis of literary translation. Dept. of Comparative Literature, University of Alberta.

Reiss, K. (2000). Possibilities and Limitations of Translation Criticism: Categories and Criteria for Proper Assessment of Translations (Erroll. F. Rhodes, Trans.). St. Jerome Pub. (Original work published 1971).

Ramière, A. (2004). A place for film dialogue analysis in subtitling courses. In P. Orero (Ed.), Topics in Audiovisual Translation (pp. 103-126). John Benjamins. https://doi.org/10.1075/BTL.56.13REM

Venuti, L. (1998). The scandals of translation: towards an ethics of difference. Routledge.

Venuti, L. (1995). The translator's invisibility: a history of translation. Routledge.

Vervecken, A. (2012). Surtitling for the Stage and Directors' Attitude: Room for Change. Routledge.

Zojer, H. (2011). Cultural references in subtitles: A measuring device for interculturality? Babel Rev. Int. Traduct. Int. J. Transl., 57(4), 394-413. https://dialnet.unirioja.es/servlet/articulo?codigo=4120851

Ritika Sinha is an Assistant Professor of English at Goswami Ganesh Dutta Sanatan Dharma College, Chandigarh. She is Masters in English from Punjab University, Chandigarh and Masters in Linguistics (First class with distinction) from Deccan College and Post Graduate and Research Institute, Pune. She is post graduate diploma holder in Mass communication (Gold Medallist) from Panjab University, Chandigarh. Her areas of interest include Translation studies, discourse analysis, media studies, phonetics and ELT. She is pursuing research work on Psycholinguistics and Language pathology. 